
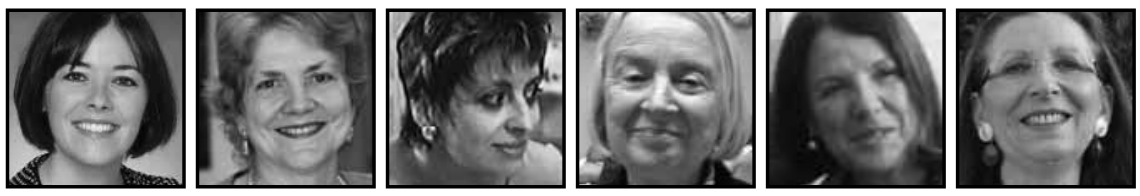

\title{
A Day at Filastrocca Preschool, Pistoia, Italy: Meaning Making Through Literacy and Creative Experience
}

Keely D. Cline, University of Nebraska-Lincoln

Carolyn Pope Edwards, University of Nebraska-Lincoln

Alga Giacomelli, Filastrocca Preschool

Lella Gandini, Liaison, Reggio Children

Donatella Giovannini, Infant/Toddler Services, Pistoia

Annalia Galardini, Crescere

\section{ABSTRACT}

In this article, ${ }^{1}$ we explore how the library teacher of an Italian preschool with a special mission focused on books, stories, and the imagination uses group literacy activities as a context for encouraging shared meaning making through creative experiences. We take readers inside one day at the Italian Preschool, Filastrocca, providing detailed descriptions and analysis of interactions and activities. We suggest that elaborate extended dialogue among children and the teacher, promotion of empathy through opportunities to take others' perspectives (including book characters'), and group engagement in shared and multi-faceted creativity are important characteristics related to meaning making in the context of relationships. Encouraging creative exploration and play across all domains of intelligence allows the children to develop their individual strengths into a product uniquely theirs.

\section{Introduction}

Empathy means the "right time." The important thing when we share daily life with children (in particular when we share moments in play) is not necessarily 
to reach an important "truth," but instead to be able to encounter one another, listening without misunderstanding, without overriding the other's meaning, in harmony based on deep, mutual familiarity.

-- Donatella Giovannini, pedagogical coordinator with Pistoia, Italy early education system (in Galardini \& Giovannini, 2001, p. 98)

... [W]ith the acquisition of speech and narrative capacities, the young child, by engaging in playful dialogues, develops imaginative capacities in which alternatives for action can be represented and expressed. Envisioning alternatives for action and multiple perspectives is a central part of the Italian experience, and it is considered by most to be an important moral sensibility.

-- Robert M. Emde, MD, in his Foreword to Bambini: The Italian Approach to Infant//Toddler Care (2001, p. xi)

Empathy, the awareness of another being's feelings; the ability to take up another being's point of view. We nurture empathy when we practice seeing the world from new and unfamiliar perspectives. Looking from a window, not into a mirror, we see another being's point of view, we imaginatively enter into another being's experience, we feel the pulse and throb of another being's heart.

--Ann Pelo (In press)

oung children are driven to learn about and understand their world. Indeed, many educators suggest that the role of meaning making, or comprehension, in children's literacy development should be given more emphasis in educational and research communities. As part of their model of "emergent comprehension," Dooley and Matthews (2009) describe interactions among adults and peers as the context in which children learn to also interact with objects-such as books - to make meaning. This shared experience spanned over time allows children to build expectations that text has purpose and meaning (Dooley, 2011). In a qualitative case study of the learning environment at an Italian preschool, Scuola Comunale dell'Infanzia La Filastrocca ("Nursery Rhyme"), we concluded that this particular school combined storytelling, imagination, and family involvement in an innovative and unique way to create a coherent, legible school environment (see Edwards et al., in press). We suggested that Filastrocca's environment promotes a community context for "emergent comprehension," in that interaction among children and adults encourages children to explore possibilities and look for the meaning contained in books and environmental print (Dooley, 2011; Dooley \& Matthews, 2009). Consistent with Dooley and Matthews' suggestions, Filastrocca's library teacher adopted an 
approach to supporting children's literacy development that focused not on basic skill preparation (e.g., decoding), but emphasized the role of meaning making through creative activity in the context of social-emotional relationships.

This paper focuses on Filastrocca Preschool, which has been among the Pistoia, Italy, schools and centers studied by visitors and researchers interested in the progressive and innovative Italian early childhood education practices (e.g., Barrs, 2007; West, 2008). Filastrocca, originally established in 1970 under the name of Fornaci ("Furnaces"), served 119 children aged 3-6 from a socioeconomically disadvantaged neighborhood in 2010 (see Edwards et al., in press, for a historical overview and in-depth description). The purpose of this paper is to expand upon our original case study and further explore Filastrocca practices, specifically through providing readers a glimpse of how literacy activities are carried out in a way that promotes emergent literacy skills and creative growth through collective imagination and through fostering empathy for peers and others. Fostering empathy has always been an explicit value of the early educational system of Pistoia (Edwards \& Gandini, 2001), drawing on attachment theory, especially as put forward by Emmi Pikler at the Loczy Institute in Budapest, Hungary (David \& Appelli, 2001). In this article, we describe and analyze a book-reading discussion and related activity observed during a 2006 visit to Filastrocca. These interactions involved a group of five-year olds and the library teacher Alga Giacomelli, a master educator in the domain of literacy, who was influential for decades in establishing and guiding the preschool's mission focused on books, stories, and the imagination.

Many visitors of the Pistoia schools and centers have been delighted by Filastrocca's distinct school culture and environment (Barrs, 2007; Edwards et al., in press; West, 2008). In this paper, we take readers inside one day at Filastrocca by providing a description and analysis of a reading conversation and related activity focused on the class's exploration of Eric Carle's The Very Busy Spider (1984), translated into Italian. It is noteworthy that the Filastrocca community has a special interest in Eric Carle; the author has established a presence in the Tuscan region over the last decade through projects designed to stimulate children's interest in books by introducing his works to teachers, educators, parents, and librarians. The interactions described in this paper occurred not long after Eric Carle made a special visit to the school to share about his books.

Filastrocca's approach to sharing books with children involves a three-stage process, first introducing a book by reading it in narrative style, and then continuing exploration with additional, interactive readings of the same book and extended 
experiences that help promote understanding and support creativity (e.g., dramatic play, painting, drawing, collage, theatre, etc.). The observation described in this paper captures the Filastrocca preschool class's second reading of The Very Busy Spider. The day before, they had read the book for a first time with Alga and started work on a project of constructing their own copies of The Very Busy Spider, involving creating a cover and inside pages of the book.

As will be presented, the rich interactions described below demonstrate several salient features related to the relationship-focused approach at Filastrocca: elaborate extended dialogue among children and the teacher; promotion of empathy through opportunities to take another's perspective, including book characters; and group engagement in shared creativity. This creativity also honors children's multiple intelligences, or "frames of mind," in the theory of Howard Gardner (1983). Children are encouraged to

...find their way to learn across the wide variety of approaches that are offered them, without there being any pressure or favour for one approach over another. The recognition of differing characteristics [of children] encourages a variety of learning styles ... The skill of the teacher is in the balancing out of the differing interests and ideas that the children bring to the group in order to arrive at a consensus, that will be taken up with enthusiasm by all the members. (West, 2008, p. 8, speaking of Gardner's theory in relation to the pedagogy she observed in Pistoia.)

As we shall lay out in the discussion section of the paper, the learning experiences at Filastrocca cultivate all of the different intelligences of children, especially (with respect to this literacy encounter) linguistic, interpersonal, and visual-spatial, but also intrapersonal, logical-mathematical, bodily-kinesthetic, and musical. We suggest that the interactions in the interactive reading and follow-up book-making experience support shared meaning making through creative activity.

\section{The Literacy Experience}

\section{And here begins the story: setting the stage.}

Alga uses familiar rituals to start literacy interactions and activities in Filastrocca's library, officially named Sfogliando l'Arcobaleno, or Paging (Leafing) through the Rainbow, but called the Rainbow Library by the children. Part of the children's library 
routine is to have their hands stamped with a red heart, a symbol associated with the children's system for rating library books (more hearts = liking the book more). When children return home from preschool with a heart stamped on their hands, parents know their child has been to the Rainbow Library that day. Children also engage in a group conversation before reading and engaging in literacy activities. The following describes interactions following the hand-stamping and discussion. Readers should also see the linked "photo story" (http://www.learnquebec.ca/learninglandscapes/ documents/Filastrocca_Preschool.pptx) that illustrates the activities through photographs and textual description.

With the book propped up in her lap, Alga announces to the group of children sitting in the circle of youth-sized chairs that they need to wait for Nicolo, another student who has run an errand, to return before they start reading. She then indicates that she also needs another student to go to the kitchen and relay a message to the staff. A couple of students volunteer, "Me!" but Alga says she needs a "big" child who can complete this errand that is a "little difficult," and requests Bianca's assistance. Just as Bianca is making her way out of the circle to run her errand, Nicolo returns.

"Go Nicolo," Alga prompts him to join his classmates. As Nicolo takes a seat, Alga initiates the activity. "First we have to sing our song, right?" she asks. Then laying the book in her lap, she starts to sway from side to side, rhythmically chanting, "Once upon a time there was a king sitting on a sofa that said to his woman, 'tell me a story."' The children join in saying the words. One boy taps his foot to the rhythm of the chant. "And the story began, once upon a time there was a king" Alga begins. Then crinkling her face in an expression that suggests she has just said something ridiculous, Alga exclaims, "Not a king!" "Who was it?” she asks as she holds up the book for the children to see.

"A spider!" the children respond.

"A little spider," Alga confirms, smiling. Still holding the book, Alga asks the child what they should do. Should they wait for Bianca to return before they start? A few sounds of disappointment come from the circle of children. Putting her hand up as if to motion, "Stop," Alga responds, "No, let's go slowly and calmly," as she opens up the book. "What could be written here on this little page?" asks Alga as she follows the words on the title page with her finger. One child speaks louder than the others to reply, "The little spider." 
"The little spider says Pietro," Alga repeats as she turns back to the cover of the book and points to the picture of the red and green spider. Opening the book again, Alga says, "And here begins the story." As she reads the words on the first page, her voice is not the only one that can be heard. A few children are trying "read" along with the teacher, saying the same words as Alga. Another little voice is making a comment or asking a question, but is drowned out by the surrounding, enthusiastic noise.

\section{Developing empathy: making spider thread and being "a little bit like a spider."}

Alga helps to transport children into the world of the spider by allowing them to pretend to do what spiders do, make threads of web. This full exploration of the character and topic has the potential to promote the widening of the children's perspective, which in turn may aid in their ability to engage with the story, topic, and representation through creative activity.

After Alga finishes reading the text about the spider on the first page, Nicholas spontaneously asks, "Why does he get stuck like that?"

"Do you remember, Nicholas? Let's show them we can make a thread." Alga prompts. Nicholas is not the only child to respond to Alga's request. Several children put their hands to their mouths, collecting saliva between their thumbs and pointer fingers. Once they have enough saliva, they hold out their hands, displaying their ability to create thin "threads" of saliva that string between their thumbs and pointer fingers. Based on their quick responses to the teacher's request to make spider web threads, it would appear that these children have tried this before. Children smile and laugh as they make their own spider web thread.

The children are still collecting saliva between their fingers when Alga says, "But Giulio was saying something important. He was saying that the spider's saliva is a special saliva. Right? Tell us why it is a special saliva."

"Because we can't do what a spider does," responds Giulio."We cannot make a spider web," Alga reiterates. This prompts a discussion among the children and teacher, with their comments sometimes overlapping.

"We are kids," says one child. 
"Let's do what kids know how to do," suggests Alga.

"We can't do what the animals do," says Giulio.

"We'll do what men and children know how to do. Even the animals don't know how to do what we know how to do," says Alga. Several children excitedly respond with their comments, prompting Alga to say, "Let's speak one at a time, otherwise we can't hear Pietro. What did you want to say?"

"Yes to everyone, we can do like this," Pietro responds, making a funny face, sticking out his tongue. Several children laugh and imitate Pietro. Alga, too, laughs, and then makes an attempt to redirect the conversation to spiders again, "But, like spiders do, you don't know how to."

"Or like a bunny," says Pietro.

"Or like a bunny," Alga repeats. Alga makes yet another attempt to redirect the conversation toward spiders. "But, Nicholas showed us before that he knows how to be a little bit like a spider. A little piece of thread. Little, little," says Alga, pointing to Nicholas and motioning how to make thread between her thumb and pointer finger (yet not using saliva).

"Me too!" respond several children and a little chatter goes on.

Not leaving anyone out: starting over for a single child.

Alga communicates the importance of each individual child when she starts the activity over for a single student.

Looking down at the book and then back up at the children, Alga asks, "Can we start because Bianca is here?" Bianca had returned a few minutes earlier and is now seated in one of the chairs. The children are still talking about their spider thread, saying, "A little bit! A little bit!"

"A little bit. Okay," responds Alga. "Bianca, sit here and we will start all over for you." Bianca is already seated, but Alga makes a special point to emphasize that they are "starting over" for her. 


\section{Reading... and interacting.}

Alga's style of interacting with children in reading and discussion is characterized by high levels of animation and enthusiastic engagement.

Now that they are "officially" started, Alga proceeds with the activity. The children attentively listen as she reads, "The splendid sun is shining. The wind is blowing. Blowing already in this good morning. It brings with it a spider in a field. The spider gets stuck on a fence and starts to build a spider web. A horse arrived and said, 'Hee-eee, hee-eee, do you want to ride on me?" Alga switches to a high-pitched voice as she reads the horse's dialogue. She returns to her "own" voice as she continues, "The little spider is quiet." The children chime in saying this last line of text. As Alga finishes reading the page, Giulio adds "Because he didn't know how to ride a horse." Alga confirms this as she turns to the next page. Alga then reads that the spider does not respond to the cow's invitation to join her in eating grass in the field. Giulio exclaims, "Because the spider eats little insects."

"He eats flies, mosquitos, bees..." starts Alga.

"The wasps," interrupts Giulio.

"Also the wasps. Everything that flies gets stuck in his spider web," says Alga. The activity proceeds with Alga animatedly reading about each of the invitations that the busy spider receives from the various farm animals to join in their doings. She shifts in to the "character voices" as she reads the animals' dialogue. "Let see who is coming. The pig arrives and says, 'Do you want to come and roll in the mud with me?"' She makes a snort as she speaks for the pig.

One child imagines himself as the spider rolling in the mud. "The little spider could drown," he says.

Alga repeats, "He could drown. He couldn't go [in the mud]. So what does he do? He makes a spider web and doesn't speak." She then picks up on words she is hearing from Bianca. "Bianca was saying that first he made a spider web like a cross."

Giulio extends Bianca's idea with another observation about the web. "He made a little circle." 
Alga repeats Giulio's idea to the whole group, and children begin to speak about the circular aspect of the spider web. They remember how they themselves drew spider webs. One child says, "Slowly, slowly. And then I made it round." Another agrees, "I made it round, too." Alga draws their thoughts together, saying, "Because he does it slowly, slowly, then he makes it round." Pointing to one child, Stella, who is making the motions with her arm, Alga says, "Look at her. How our friend is doing it. Because the spider does it small, small, and then, big, big, big. Show us, Giulio, so we can do it together. And then how our friend, Stella, taught us. Like this, like this." The children use their bodies to practice how the spider produces thread and how it spins a web-rotating their arms in smaller, then increasing larger, concentric circles.

Not so different from spiders: it's like when we eat some animals.

Children next have another rich opportunity to develop empathy by first attending to the situation of a fly that becomes a meal for a spider, and then contemplating a parallel between spiders and people.

"Now let's see what happens. Let's see if he is able to catch the fly. What do you all think? Do you think he will catch the fly?" Alga asks.

"Yes," a child responds.

"He did it," Alga says, and continues reading, "But first a rooster arrived and said 'Cock-a-doodle-do, why don't we go together to catch a fly?' The spider is quiet. He already caught the fly. So do you think this is the same fly?" Alga poses the question to the children, who respond that they think it is. Alga continues, "Is it the same fly that is stuck in the spider web, what do you think? Poor fly. After all, he eats flies like we eat ice cream."

"It's like when we eat some animals," a girl named Stella suggests.

"Sure, good job. Stella said something very right. Did you hear what Stella said? She said, it's true that the spider ate the fly, but we eat meat, too," says Alga.

Children name different meats, "Fish, and rabbits, chicken..." 


\section{How much did you like it?}

Children engage in a procedure of quantifying how much they like the book that is specifically adapted for their level. This verbal method corresponds with their usual procedure of evaluating library books that involves children rating books by assigning a number of hearts (more hearts equates to liking the book more) (Edwards et al., in press).

Upon finishing reading, Alga elicits children's opinions about the book. After a few children respond that they like the book, but provide little description about what they like or how much they like it, Alga asks, "Which page did you like? Kids, think about it."

"The one with the owl," responds Nicolo.

"The one with the owl. This one," Alga says with the book open to the page with the owl. "You like this one best? How much would you give it? A heart? A lot? A whole lot? What would you give it? A kiss?" Alga tries to get Nicolo to describe how much he likes in a way that the children can understand.

"A lot," responds Nicolo. "Me too," says Nicholas.

"Let's listen to Nicholas," says Alga.

"I liked it a lot, a lot, a lot," the boy responds.

Alga says, "Nicolas liked it a lot, a lot, a lot. Three a lots. What page did you like the most?"

"If you turn to it, l'Il tell you," says Nicholas.

"I'll turn the pages and you tell me. This one? This one?" Alga says flipping through the pages. Nicholas responds "no" until Alga turns to the owl.

This initiates the start of an animated book review. Children take turns sharing which animals they like the best and how many "a lots" they like the book. After Isacco reviews the book, Alga exclaims, "Wow! He liked it even more [than the student who said he liked it 7 a lots]! Let's repeat with 
Isacco." Then counting on her fingers, with the children following along, she says, "A lot, a lot, a lot..." until she is holding up eight fingers.

\section{Finishing the book that we started yesterday.}

As previously described, Filastrocca's method of reading books involves: introducing in narrative style and then investigating more through interactive readings and creative activities. The children extend their understanding of the book by engaging with the material in various ways over multiple days.

As the children finish their reviews, Alga suggests, "We need to clap for this book. Shall we do it?" The children jump up from their chairs and enthusiastically applaud, many looking around, exchanging beaming smiles with their peers. Alga helps the children transition to their next related activity by responding to one child's request and announcing, "Nicholas was saying something. Say it to everybody. Nicholas was saying that he wanted to finish the book that we started yesterday. Go sit at the table and then we'll start." Alga hands the book in her hand to one child as she goes to prepare for the activity. Several children crowd around the book-holder to catch a glimpse of and touch the book.

\section{Opening shop: adding pretend play.}

In the next section, the children and teacher are transported to a makebelieve shop where they can negotiate the prices of the supplies needed to complete their book covers.

The children seat themselves around a table. In front of them, they have the little handmade books. Alga moves from child to child, helping to staple a colorful piece of paper (book cover) around the pages that each child started the day before. Children also have scissors and glue. Alga sits at a smaller table to the side of the children's table. On her table, the The Very Busy Spider book is displayed. Additionally, there are containers of paper of varying colors, sizes, and shapes. Alga says, "Now we'll open another shop. It's a shop that sells many papers of all colors. Nicholas and Sara came to buy, let's see what they buy." Children take turns "buying" their supplies from Alga, reaching into their pockets to pull out invisible money which they hand over to Alga before returning to their seats with the paper "purchases" that they craft into fences, spiders and webs upon their return to their table. Many children cut strips to go around their cover, just like the wooden frame 
they had seen portrayed in Eric Carle's story. Some children focus more on representing the body of the spider, and others more on the shape of the web.

They discuss the price of the paper with one another and Alga.

"How much is it?" one child asks about a piece of paper that Alga suggests would make a good spider web.

Nicholas indicates, "One hundred million Lire." Alga responds, "No that is too much, [instead] one hundred Lire." The children continue to "buy" supplies and work on their books. At one point, Alga says one child owes 100 Lire.

He says, “No, 90."

Alga responds to the bargaining, "My goodness! Pay, okay here's the change. Take the change. Hey guys, I became rich today selling. You all paid me a lot of money." The children continue to converse among themselves and with Alga as they intently paste paper in their books and use markers to add to their books. Alga offers, "Would you all like some music? Should I put a little music on?"

"Yes!," children respond in unison.

"The one with the Lions," one child requests, referring to the 5 -yearold's class symbol. With the music now playing in the background and Alga seated at the table with the children as they work on, there is discussion of the children's books and choice of supplies.

The title: Bianca writes it and Alga photocopies it.

Alga utilizes an individual student's contributions to provide resources for the entire group.

Alga asks, "Listen, does anyone want to maybe put on the title of this book?" Several children respond, "I do."

“How do we do it? Why doesn't Bianca write it and Alga goes to photocopy?" Alga suggests. Bianca has a strip of paper on which to write the 
title of the book. Though Bianca is ready, Alga is talking with Nicholas and says, "Hold on, Bianca, one moment. This is something important. Nicholas would like some very little things to attach on these strips. He would like to put the little animals."

Upon discussing Nicholas's ideas and helping him with his supplies, Alga returns to the topic of the title saying, "Listen kids, to this idea of Nicholas. That is cute but Alga has to go make a copy. Listen, Sara, would you like to put on the title? Tell me one thing, who would like the title of the book?" All of the children raise their hands, "Me!" "Oh my gosh, everyone wants to. We need to decide something. Bianca will write it, and Alga will photocopy it. Okay?"

"Me too," one child says.

"With all of us, it would take too long. No, Bianca, I'll give you a strip. You can write on it and then..." Alga starts as she addresses Bianca.

Once Bianca has the strip of paper and marker, Alga asks, "Do you want to write all of the title of the book? The Little Spider Who Spins a Web in Silence?"

“Yes, but it doesn't fit," responds Bianca.

"Little, little, write little," suggests Alga. Alga sits next to Bianca, giving her instruction and watching intently as she writes the words on the strip of paper.

Upon Bianca's completion of the writing, Alga asks, "Okay, who wants Bianca's writing, The Little Spider Who Spins a Web in Silence?" Once the copies are made, Alga uses a paper cutter to cut the little strips of paper. Children trim the paper strips with scissors and paste them onto their elaborately decorated book covers, continuing to talk about their work with one another and Alga as they do so.

\section{"Tell me everything about this book."}

Alga gives children the opportunity to explain their books while she records the descriptions. Children are allowed to finish at their own pace. 
As children near completion of their books, Alga signals the end of the activity by saying, "Today our friends Nicolo and Nicholas will have a lot to do. Yes, you have to put the room back. Who is going to help clean the room? Cleaning the table."

With the title pasted onto the cover, Isacco, beaming with pride, holds his book up to show Alga across the table. Alga says, "Look at Isacco's. He has finished. It came out really well. Look! A beautiful cover page."

Issaco comes over to Alga's table. "Listen, do you want to tell me something you want me to write inside? Let's do this, how the lady that sells, if you want, will be at this table," Alga gestures to the little table with the paper and supplies. "When you are done if you want to come to tell her something about your book, you can come, okay. Come, honey. Sit," Alga says to Isacco as they go to the supply table together. Alga and Isacco discuss Isacco's book, with Alga complimenting him on it. Another child comes up to Alga, explaining that his title will not fit on the cover. Alga suggests, "If you would have put it on top of the circle it would have fit. You can leave it like that. It is missing the little eyes," she points out of the child's spider before he returns to the table. Directing her attention back to Isacco, Alga says, with Isacco's book opened to the last page and her pen poised to write down his responses, "Okay, tell me everything about this book. Did you like the story of the spider?" Isacco tells Alga it is the story of the spider.

"It's the story of the spider. Is that it? You don't want to write anything else?" Alga asks as she writes. Since Isacco doesn't say anything further, Alga accepts that he is finished. "Very nice," she says, "Let's put this book that you have finished, down to dry." Alga attends to the other children about their books, helping them to put their books up on the shelf to dry. Children who are finished select books in the library to independently read as Alga continues to assist until all children are finished.

\section{Discussion}

The pace of the above-described activities was relaxed and flowing without distinct "starts" and "stops." A rhythmic chant preceded the reading of the book and helped the children to recognize that they were going to be starting the story. As Alga and the children explored the first pages, they not only focused on the text, but 
also spontaneously pretended to make spider webs. Although they had already read some of the book, Alga restarted the story on behalf of one child who had missed the beginning. Much dialogue surrounded the reading, and this discussion was characterized by extensive turn-taking. At the conclusion of the reading of the book, children were invited to provide their reviews and evaluate how much they liked the story, eliciting many repetitions of "a lot, a lot, a lot..." The discussion surrounding the reading of the book lasted nearly 20 minutes. As children gathered around the table to continue making their own versions of the book, children simultaneously worked on their projects and conversed with one another and Alga as music played in the background. Children appeared serious about their work while at the same time enjoying the company around them. The activity concluded with the children discussing their books with Alga. This atmosphere, relatively free of prompts to hurry or rush, allowed children time to have time to engage with one another in collective experience and form new creative ideas.

We suggest that this relationships-focused setting provided opportunities for engagement in creative activity and interactions that promoted shared meaning making. The children and teacher gained a deeper and shared understanding of topics of interest through extended dialogue. Through this conversation and related activities (e.g., making spider webs from saliva), the class develops empathy for the spider. The book does not afford any particular supports for relating to the character-he does not speak; he displays no emotion; he simply weaves a web in silence as other animal characters try to engage him with no success. By comparing their own actions (i.e., diets) to those of the spider and being a little like a spider by making webs, the children move a little closer to feeling the spider's feelings and experiencing the spider's experiences. Is this important? We suggest that it equips the children for more effectively making meaning of books and shared experiences. This more advanced meaning making is also a product of children's related creative activity; as children work both individually and collaboratively to represent the book through creating their own versions, they are expanding the depth of their understanding of the original children's literature story.

Finally, the experience at Filastrocca fostered creative learning in young children by allowing them to engage their voices and bodies, stretch their imaginations, and employ all their approaches to learning. Table 1 indicates that each of the seven approaches described by Howard Gardner (1983) in Frames of Mind: The Theory of Multiple Intelligences, was stimulated in at least two episodes of the observed book reading and cover making. Encouraging creative exploration and play across all domains of intelligence helps young children to develop their individual strengths and even 
combine elements of several domains into a process and product uniquely theirs. In this encounter, creativity was fostered through oral storytelling and extended discussion; quantifying and evaluating; interactive and imaginative role-playing; reflecting on their likes and dislikes; attention to everyone in the group; employing a variety of artistic techniques and materials; and rhythmic chanting and listening to music.

\section{Table 1}

THE MULTIPLE INTELLIGENCES (GARDNER, 1983)

Linguistic intelligence has to do with the ability to use words, spoken or written
Interpersonal intelligence has to do with interaction with others and understanding others
EXAMPLE(S) AND DESCRIPTIONS OF OBSERVED INTERACTIONS ENCOURAGING EACH TYPE OF INTELLIGENCE

Developing Empathy: Making Spider Thread and Being " $a$ Little Bit Like a Spider." The children engaged in complex discussions of the book, for example, when they talked about the differences between what humans and spiders can do and how the spider spins its web.

Not So Different From Spiders. The verbal interaction continued as they compared the spider eating flies to children eating meat.

The Title: Bianca Writes It and Alga Photocopies It. Children integrated writing into their cover-making activity; one child wrote out the title of the book and the other children used photocopied slips of paper to paste onto their book covers.

Tell Me Everything About This Book. Spoken and written words were integrated for the children when Alga asked them individually to explain their books while she recorded their descriptions.

And Here Begins the Story. The children interacted with one another through shared, familiar rituals, including having their hands stamped with the library symbol and engaging in discussion before reading.

Not Leaving Anyone Out. Alga communicated the importance of each individual as part of the group, when she started the reading of the book over for a single child, Bianca, who returned to the class after running an errand. 
Reading... and Interacting. The children were encouraged to develop empathy and widen their ability to take another's perspective by pretending to do what spiders do-make threads of web.

The Title: Bianca Writes It and Alga Photocopies It. Alga promoted a cooperative spirit and appreciation of others' strengths by allowing Bianca to apply her good lettering skills to copy the title of the book for everyone to use.

Visual-Spatial intelligence has to do with spatial judgment, visual patterns, and the ability to visualize with the mind's eye
Opening Shop. The children decided how to design their book covers and utilize the space on their pages. Many children cut paper strips to frame their cover, replicating the wooden frame they had seen portrayed in the original story. Some children worked to represent the body of the spider, while others focused on representing the concentric circles that were part of the web.

The Title: Bianca Writes It and Alga Photocopies It. To complete their covers, each child arranged and pasted a strip of paper with the book title onto his or her cover.

How Much Did You Like It? The children were encouraged to reflect on their own likes and dislikes as they chose which animals they liked the best in the story and rated how much they liked the book.

Finishing the Book That We Started Yesterday. The children also expressed their appreciation for the book by clapping for it.

\section{Logical-Mathematical} intelligence has to do with numbers, logic, abstractions, reasoning, and critical thinking
How Much Did You Like It? The children quantified how much they each liked the book by evaluating how many "tanto's" ("a lot's") it was worth.

Opening Shop. Alga helped children explore the concept of the corresponding value of objects and money, as she "sold" art supplies to them to make their books. 
Bodily-Kinesthetic intelligence has to do with control of one's bodily motions and the capacity to handle objects skillfully

Reading ... and Interacting. The children used their mouths and fingers to illustrate how spiders produce thread; they stretched strings of saliva between their thumbs and pointer fingers. They also pretended to be spiders spinning their webs, rotating their arms through the air in first smaller, and then increasing larger concentric circles.

Opening Shop. The activity of making book covers involved physically manipulating objects and art materials as they cut, arranged, and pasted pieces of paper and employed markers to draw and represent spider, web, and other elements of the story.

\section{Musical intelligence} has to do with sensitivity to sounds, rhythms, tones, and music
And Here Begins the Story: Alga began the book reading with a rhythmic set of familiar words, "Once upon a time..." and the children joined in. One boy tapped his foot to the rhythm of the chant.

Opening Shop: The children all responded, "Yes!" to Alga's suggestion to have music playing in the background as they worked on their books.

In conclusion, we suggest that the observations of Filastrocca Preschool described in this paper provide an illustration of how shared extended discourse, promotion of empathy, and shared and multifaceted creative activity can be intertwined in the process of meaning making in the context of relationships.

\section{Note}

1. We gratefully acknowledge the children, families, and teachers of Filastrocca Preschool as the co-creators of this article; and thank the educational officials and public administrators of the Municipality of Pistoia for their openness to our studies. Silvia Betta assisted in the translation of the documents. The University of Nebraska-Lincoln generously supported the research and publication efforts of Carolyn Edwards. 


\section{References}

Barrs, M. (2007). The creative community of Pistoia. Teaching, Thinking, \& Creativity, 8(1), 18-27.

Carle, E. (1984). The very busy spider. New York: Philomel Books.

David, M., \& Appelli, G. (2001). Lóczy: An unusual approach to mothering. Los Angeles: Resources for Infant Educarers.

Dooley, C. M. (2011). The emergence of comprehension: A decade of research 2000-2010. International Electronic Journal of Elementary Education, 4(1), 169-184.

Dooley, C. M., \& Matthews, M. W. (2009). Emergent comprehension: Understanding comprehension development among young literacy learners. Journal of Early Childhood Literacy, 9(3), 269-294.

Edwards, C. P., Cline, K. D., Gandini, L., Giacomelli, A., Giovannini, D., \& Galardini, A. (In press). Books, stories, and the imagination at 'The Nursery Rhyme': A qualitative case study of the learning environment at an Italian preschool. Journal of Research in Childhood Education, in press.

Edwards, C. P., \& Gandini, L. (2001). Research as a partnership for learning together: Studying the growth of relationships inside the nido. In L. Gandini \& C. P. Edwards (Eds.), Bambini: Italian experiences of infant and toddler care (pp. 181-199). New York: Teachers College Press.
Emde, R. M. (2001). Foreword. In L. Gandini \& C. P. Edwards (Eds.), Bambini: Italian experiences of infant and toddler care (pp. viixiv). New York: Teachers College Press.

Galardini, A., \& Giovannini, D. (2001). Pistoia: Creating a dynamic, open system to serve children, families and community. In L. Gandini \& C. P. Edwards (Eds.), Bambini: Italian experiences of infant and toddler care (pp. 89-105). New York: Teachers College Press.

Gardner, H. (1983). Frames of mind: The theory of multiple intelligences. New York: Basic Books.

Pelo, A. (In press). The goodness of rain: Developing an ecological identity in children. Redmond, WA: Exchange Press.

West, V. (2008). Architecture, space, and pedagogy in Pistoia. Staffordshire University, United Kingdom. Retrieved from http:// www.inter-disciplinary.net/at-the-inter face/wp-content/uploads/2012/05/Archi tecture-Space-and-Pedagogy-in-Pistoiatext-final.pdf 


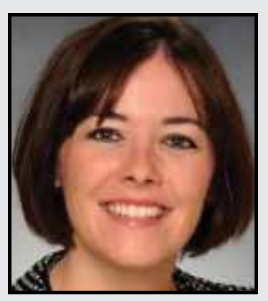

Keely D. Cline works with the Nebraska Center for Research on Children, Youth, Families and Schools (CYFS) at the University of Nebraska-Lincoln. She has studied Filastrocca Preschool and participated in a study tour to Pistoia in May 2010. Her research interests include understanding strategies for supporting young children's literacy and language development. She is currently the project director of an Institute of Education Sciences funded research project focused on assessing the effects of an intervention designed to promote children's school readiness through parent engagement and parent-teacher relationships.

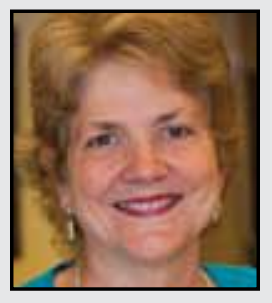

Carolyn Pope Edwards is Willa Cather Professor at the University of Nebraska-Lincoln. She has visited Pistoia numerous times, most recently while also participating in a study tour to Pistoia in March, 2012. She co-edited Bambini: The Italian Approach to Infant/Toddler Caregiving (Teachers College Press, 2001), with Lella Gandini, as well as the accompanying video on Pistoia (available from Learning Materials Workshop.) Among her publications are The Hundred Languages of Children, $3^{\text {rd }}$ Ed.: The Reggio Emilia Experience in Transformation (with Lella Gandini and George Forman, 2012) and The Diary of Laura: Perspectives on a Reggio Emilia Diary (with Carolina Rinaldi, 2008).

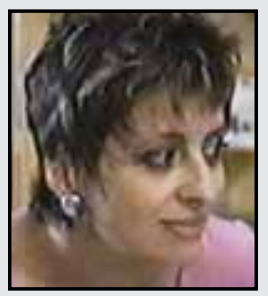

Alga Giacomelli, recently retired, was for many years the library teacher at Filastrocca preschool in Pistoia, a school for children from 3 to 6 years of age. She designed the lending library for parents, run by children, and a program that includes the invention of stories, as well as the design and illustration of books by children. 


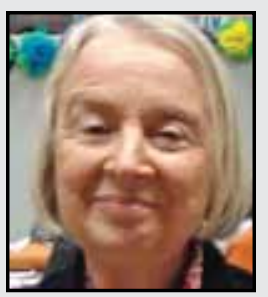

Lella Gandini, Visiting Scholar at Lesley University in Cambridge 2007-2009 and at the University of Arizona 2010, introduced the Italian education of young children from Pistoia and Reggio Emilia in the United States in the early 1980s. For Reggio Children, she serves as the Liaison for the Dissemination of the Reggio Emilia Approach. She is co-author and co-editor of The Hundred Languages of Children; Bambini: The Italian Approach to Infant/Toddler Care; Beautiful Stuff; In the Spirit of the Studio: Learning from the Atelier of Reggio Emilia; and Insights and Inspirations from Reggio Emilia: Stories of Teachers and Children from North America.

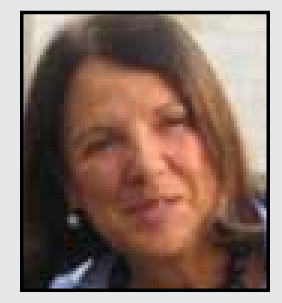

Donatella Giovannini is Pedagogical Coordinator for Infant/Toddler Services of Pistoia, Italy. She is involved in research carried out by the Psychology Institute of the National Research Council in Rome and in collaboration with several European programs for young children. She has published many articles and book chapters and has been instrumental in supporting the professional development of infant-toddler educators in Pistoia and its sister city, Palermo.

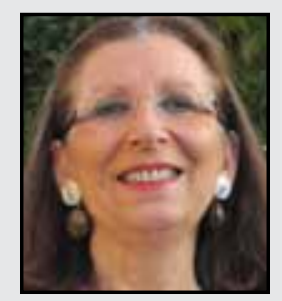

Annalia Galardini was a founding leader of early childhood services in Pistoia, Italy and Director of Education, Social Services, and Cultural Affairs in the city administration. She is now President of Crescere, providing professional development in the Tuscan region. Prominent at the national and international levels, she has organized in-service workshops in several Italian cities and published articles, chapters, and books about the organization and goals of family-centered services for young children. 